\title{
Willingness of residents to invest in flood mitigation measures and to purchase flood insurance
}

\author{
Sari Väisänen ${ }^{1 a}$, Virpi Lehtoranta ${ }^{1}$, Antti Parjanne $^{1}$, Anne-Mari Rytkönen $^{2}$ and Juha Aaltonen ${ }^{1}$ \\ ${ }^{1}$ Finnish Environment Institute, Water Centre, P. O. Box 140, FI-00251 Helsinki, Finland \\ ${ }^{2}$ Finnish Environment Institute, Water Centre, P. O. Box 413, Fl-90014 Oulu University, Oulu, Finland
}

\begin{abstract}
Approximately 12,000 people live in the flood risk areas in Finland. New flood risk management plans were prepared for 21 areas as a part of the EU Floods Directive in 2015. In connection with this work, we conducted a survey in three flood risk areas in 2014 . The total number of recipients was 4,710 and the response rate $39 \%$. The study provided an indication of how local citizens perceive flood risk, and specifically whether they have already invested or would be willing to invest in private flood mitigation measures or to purchase flood insurance. We also examined how previous personal experiences of flooding affected their responses. The questionnaires were georeferenced in GIS and compared with flood hazard maps on a detailed scale. Over $27 \%$ of the respondents had experienced a recent flooding event, but only $9 \%$ had implemented flood mitigation measures and $10 \%$ knew that flood coverage was included in their insurance. A young age and having property at risk of flooding increased the willingness of respondents to consider implementing flood protection measures and purchasing flood insurance.
\end{abstract}

\section{Introduction}

In recent years, flood management has increasingly shifted to more integrated approaches in Europe (the EU Floods Directive; 2007/60/EC). The development of flood management in Finland also requires private households to take more responsibility for flood mitigation measures, i.e. through the use of flood protection devices and/or purchasing of "flood" insurance.

Some studies [e.g. 1, 2] have suggested that massive flood protection constructions are not sustainable solutions in the long term. Instead, greater emphasis should be placed on flood mitigation measures implemented by private households. This makes it even more important to recognize the factors that are significant in promoting such activities and to deliver useful information to residents.

A growing number of empirical studies have recently investigated the factors that drive private mitigation behavior, among which flood risk perceptions have been the most dominant [3]. A large number of empirical studies have investigated risk perceptions and personal actions, but the relationship between perceptions and the behavioral response relative to preparedness is still unclear and controversial [4]. Although a number of studies have addressed the issue of how to create incentives for households to control and reduce flood damage though insurance, empirical analyses of the

\footnotetext{
${ }^{a}$ Corresponding author: sari.vaisanen@environment.fi
}

effectiveness of such incentives are rare [1]. Current empirical research on mitigation behavior lacks information on studies that deter people from adopting precautionary measures; the perceived effectiveness of flood mitigation measures has received relatively little attention in the current literature on mitigation behavior [1].

Botzen et al. [3] studied the willingness of Dutch households to undertake voluntary mitigation measures for insurance benefits. Zaleskiewicz et al. [5] examined the factors that influence people's decision to buy flood insurance in Poland. They revealed that fear predominantly determines whether people are interested in purchasing flood insurance. In a recent study in Canada, $52 \%$ of respondents indicated that they would be willing to pay for flood insurance [6].

Many Canadians falsely believe that their home insurance covers damage caused by overland flooding. Oulahen [6] applied independent samples tests to identify the determinants of residential vulnerability to flood hazards.

The aim of this study was to assess the willingness of individuals to implement or consider implementing mitigation measures and to purchase or consider purchasing flood insurance in three significant flood risk areas in Finland. We were interested in revealing whether the same or different factors influence these two intentions to reduce flood risk. 


\section{Flood management in Finland}

There are 21 significant flood risk areas in Finland, with approximately 12,000 people living in a flood-prone area (100-year flood). New flood risk management plans were prepared for these areas in 2015 as a part of implementing the EU Floods Directive (2007/60/EC).

\subsection{Flood risk management}

The purpose of flood risk management is to reduce flood risks, prevent and mitigate the adverse consequences, and promote preparedness for floods. The main focus is on reducing adverse consequences to human health or safety with use of means other than those based on flood protection structures whenever possible.

In recent years, flood damage to built environments in Finland has amounted to roughly 5-10 million euros per year. The government's investments in flood risk management have been slightly decreasing. A shift in responsibilities for the compensation of flood damage has also emphasized the importance of self-preparedness.

Residents are suggested to be responsible for or participatory operators in 66 measures out of the more than 410 flood risk management measures determined in the flood risk management plans. In addition, many other measures aim at increasing awareness among inhabitants and flood risk preparedness. Informing the population about flood risks and what to do in the event of a flood have been identified as measures to be improved compared to the present situation.

\subsection{From public to private insurance}

Mostly due to historical farmland flood protection, the level of protection in many areas in Finland is currently only for floods occurring statistically once in twenty $(1 / 20 a)$ or once in fifty $(1 / 50 a)$ years, while the objectives in flood risk management plans are set for $1 / 100$ or $1 / 250$ a floods.

At the beginning of 2014, the Finnish government ended the compensation system for flood damage: the state ceased compensating damage to buildings or personal property caused by exceptional floods. By reforming the flood damage compensation system, Finland followed the example of other European countries such as Germany, France, and the UK, where flood damage is covered by private insurance. Exceptional flood damage is now compensated through private insurance policies as part of extensive home and real-estate insurance ${ }^{b}$. Under the current conditions of insurance policies, the term 'exceptional' means a flood occurring statistically once in 50 years or less frequently, while earlier, in the state's compensation system, it meant a $1 / 20$ a flood. Due to this change, it is likely that no flood damage compensation mechanism will be available

\footnotetext{
${ }^{\mathrm{b}}$ Each insurance company has priced its own products on the basis of risk assessment. In the future, actualized damage will affect premium prices.
}

that covers damage caused by floods occurring more often than once in 50 years.

In practice, all the largest Finnish insurance companies have included flood security in home and realestate insurance policies. Thus, homeowners do not need to purchase separate flood insurance, since the great majority of Finnish households have voluntary home insurance. To date, the addition of coverage for flood damage has not raised the cost of insurance premiums. However, despite the information provided by insurance companies, many people are still not aware of these alterations.

Before the switch to an insurance-based flood compensation mechanism, it was also in the government's interest to invest in flood protection in order to avoid compensation payments. Following the shift to an insurance-based system, the government's role in both compensation and flood protection has at least to some degree changed, and more focus is now placed on the responsibilities of residents. On this point, if property owners have not taken much action in flood preparedness, and because compensation practices have changed, it is important to inform and share knowledge with citizens.

\section{The application}

\subsection{Three study areas}

The survey was conducted in three flood risk areas in western Finland. The areas were selected to represent a wide range of Finnish inland waterways, from one of the largest catchments with years of significant flood protection to a small catchment that had only recently faced its first significant flooding (Figure 1).

On a European scale, these areas mostly represent sparsely populated small and low-lying catchments that are not usually the main targets for flood risk management. Nevertheless, although the study areas could not be compared to the main rivers of Central Europe, ice jam flooding, which is characteristic of the three study areas, has often rapidly arisen, similarly to flash floods or debris floods. Furthermore, the study areas are located in areas with a low proportion of lakes by Finnish standards, which makes flood risk management and the study results more comparable to other countries.

The city of Huittinen is one of the 21 significant flood risk areas in Finland and is located on the lower reaches of Kokemäenjoki River (catchment ca. 27,000 $\mathrm{km}^{2}$ ), having an average flow of $245 \mathrm{~m}^{3} / \mathrm{s}$. Huittinen is located in an area of flat agricultural land in the central part of the main river. The city of Pori at the river delta is the most significant flood risk area in Finland. The upper reaches of Kokemäenjoki River have a high proportion of lakes $(11 \%$ of the whole catchment area), most of which are regulated. Despite the floods that inundate agricultural fields almost yearly, the main aims of flood risk management are to protect residential buildings and the wastewater treatment plant in open water and ice jam flood situations. One of the measures suggested in the 
flood risk management plan of the area is a bypass channel in the Säpilä area. The channel has been part of the flood-related discussion for decades, and has therefore partially helped to maintain flood awareness among residents.

Kalajoki is a mid-sized $\left(4,247 \mathrm{~km}^{2}\right)$ lowland river with a total length of $130 \mathrm{~km}$ and a mean discharge of about $30 \mathrm{~m}^{3} / \mathrm{s}$. The Kalajoki river basin is mainly a rural area with a total population of 48,000 , including the significant flood risk area of Alavieska-Ylivieska. Due to the low proportion of lakes $(1.8 \%)$, the river basin is characterized by large intra-seasonal variations in discharge, resulting in frequent floods and low discharge in dry periods. Drainage and dredging projects in the river basin have accelerated the runoff. In addition, flood embankments have reduced the size of natural flood plains. The highest discharges occur in spring, but increased winter discharges may, for example, increase the risk of frazil ice dams (Veijalainen et al 2009).

The Lapväärtinjoki River catchment is rather small $\left(1,100 \mathrm{~km}^{2}\right.$, length of $\left.75 \mathrm{~km}\right)$ but with a $160 \mathrm{~m}$ drop height and only $0.2 \%$ areal coverage with lakes. The average flow is $13 \mathrm{~m}^{3} / \mathrm{s}$. The city of Lapväärtti is located on a lowland area close to the river delta, which makes it vulnerable to rapid floods, especially ice jam floods. Lapväärtti was not designated as a significant flood risk area, but after suffering from serious flooding in autumn 2012 and again from ice jam flooding in spring 2013, flood risk maps and management plans have been prepared for the area similarly to the other significant risk areas in Finland. New embankments were constructed and dredging was carried out.

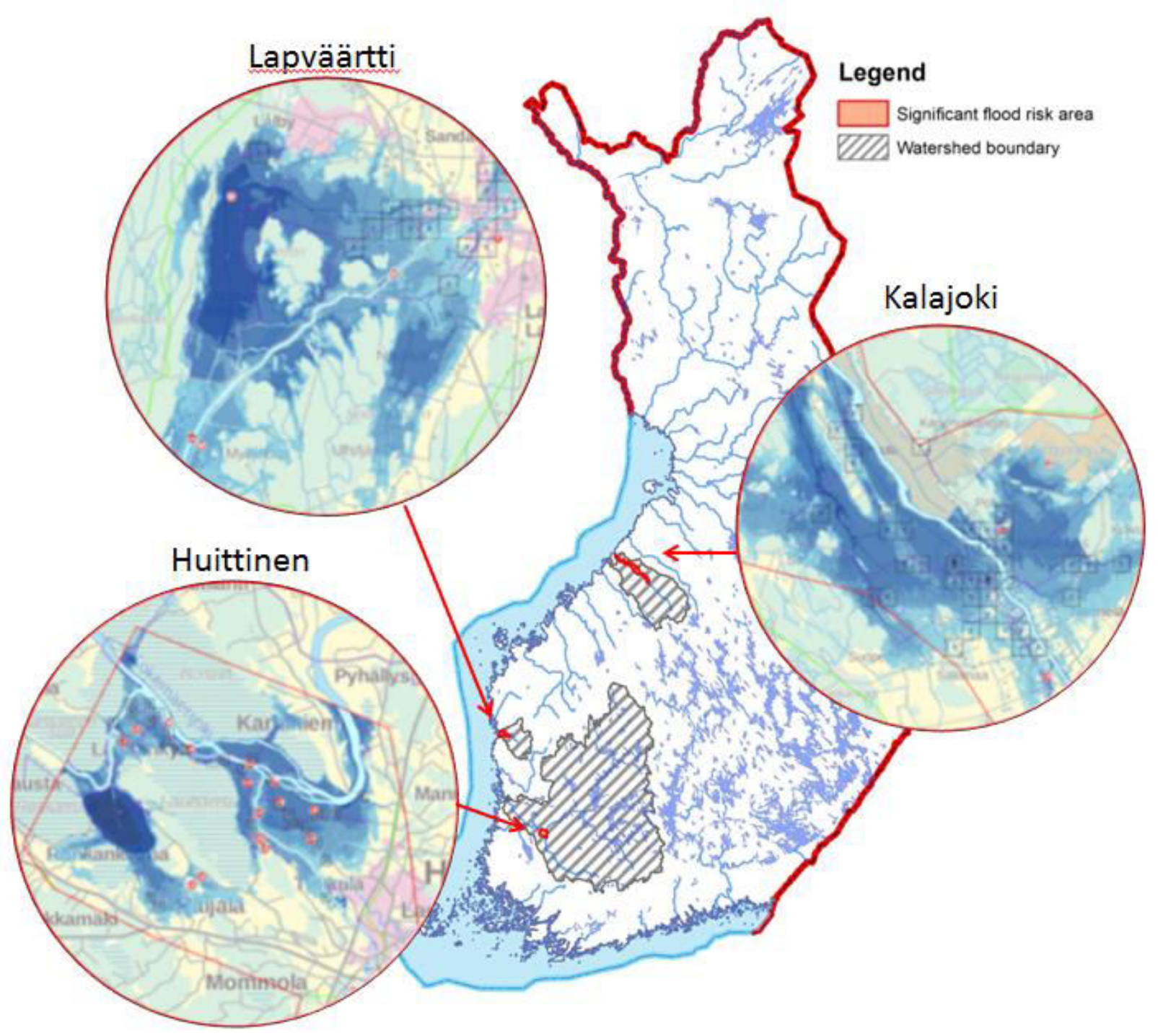

Figure 1. Location of the three study areas and examples of their flood risk characteristics. Whole flood maps for the areas can be found from www.environment.fi/floodmaps. 


\subsection{Methods}

The survey sample was drawn from a census register provided by the Finnish Population Register Centre. The questionnaires were sent to all the households in the significant flood risk areas of Kalajoki and Huittinen. The recipient was chosen to be the eldest person of the household and between the age of 18 and 75 years. The study area of Huittinen was extended so that all the households within $500 \mathrm{~m}$ from the flood hazard area (floods occurring statistically once in a thousand years) were also included. Because Lapväärtti is not yet designated as a significant flood risk area, the study area was the river basin and all of its households.

The questionnaire procedure followed Dillman's protocol [7], with the recipients being contacted three times. The sample included a total of 4,790 households ${ }^{\mathrm{c}}$, and 1,858 responses were returned ( $38.8 \%$ response rate).

The questionnaires included questions about the respondents' experiences of floods, opinions about flood protection measures, flood-related information and socioeconomics. There was also a description of the change in the compensation party from the government to insurance companies and a reminder that without insurance, the homeowner is now even responsible for severe flood damage.

The main interest was in determining whether the respondents had implemented any private flood mitigation measures and if they knew or assumed they already had flood coverage in their existing insurance, or if they might consider purchasing such insurance. These latter valuation questions were constructed in the contingent valuation method style, which is the most frequently applied method in valuing environmental assets [8]. However, the monetary amounts of the willingness to pay (WTP) for private mitigation measures are not the focus of this paper.

The questionnaires were also georeferenced. In other words, each address of the respondent was connected to the Building and Dwelling Register (referred as BDR) maintained by the Finnish Population Register Centre. In the BDR, each building has coordinates that can be further utilized in GIS analyses. For this study, the location of each building was intersected with flood hazard maps including flooding probabilities.

In addition to the information on whether a building was located in a flood hazard area, coarse-scale information on the flood water depth was also obtained. Furthermore, the distance from each building to the nearest river reach represented in the Finnish River Reach Register was also calculated. However, this does not necessarily mean the shortest distance to a water body, as lakes and smaller ponds were not taken into account. All of the case study areas were defined as river flood risk areas, so the distance was calculated to the most probable flood source.

\footnotetext{
${ }^{c}$ The survey questionnaires were sent to every household in the Kalajoki and Huittinen areas and every other household in the Lapväärti area.
}

We applied binary logistic regression models to reveal similarities and differences in the willingness of respondents to consider implementing flood protection measures or to extend their home insurance to include flood compensation.

\section{Results}

\subsection{Sample characteristics and descriptive statistics}

The average age of all the respondents was 58 years (AGE, see Table 1). The gender distribution of the respondents might be skewed, as $39 \%$ of the respondents were women (FEMA). The questionnaires were sent to the oldest person in household About $17 \%$ of the respondents categorized themselves as forest or agriculture entrepreneurs (ENTR) and about 11\% lived in an apartment house $(A P A R)$.

Based on the results, $41 \%$ of the respondents perceived themselves as living in an area with a high risk of fluvial flooding (RISK). According to GIS analysis, about one respondent out of ten actually lives on real estate at risk of inundation in the case of a fluvial flood (WRIS). The flood risk areas are delineated by local environmental authorities, who rely on hydraulic modeling and flood mapping, excluding sewage and pluvial flooding. This expert opinion may for various reasons differ from the view of the residents living in the area. Furthermore, it is likely that those with experience of flood damage or disturbance, or with a feeling of being at risk, were more keen to participate in the study.

More than one in four respondents had experienced damage or disturbance caused by flooding (DAMA). However, only $9 \%$ of the respondents had implemented flood protection measures (IMPL). This suggests that experience of damage or disturbance due to flooding may also be associated with minor harm, e.g. road closures or damage, rather than only the possibility of having water rising to the level of one's building. Approximately $8 \%$ of the respondents would consider implementing flood protection measures on their own real estate (WTP). Less than one-fifth of the respondents would consider extending their home insurance to include flood damage compensation (CONS), while only one-tenth of the respondents were aware that they already had such insurance (INSU). Over half of the respondents owned some property in danger of flooding $(P R O P)$.

One out of five respondents felt that their household could influence the damage caused by fluvial floods (ATTI). Almost half trusted in the ability of the authorities to plan flood mitigation measures (TRUS), and about $30 \%$ received new information about floods from the questionnaire $(I N F O)$. The variable DIST describes the distance of the respondent's house from the nearest river or stream, i.e. the potential origin of fluvial floods. Most of the respondents lived near a watercourse, being approximately $445 \mathrm{~m}$ from the nearest river. 


\begin{tabular}{|c|c|c|c|c|c|}
\hline Variable & & Mean & SD & Min. & Max. \\
\hline AGE & Age & 57.8 & 12.97 & 15 & 87 \\
\hline FEMA & Female & 0.385 & 0.487 & 0 & 1 \\
\hline ENTR & Entrepreneur (agriculture/forestry) & 0.17 & 0.376 & 0 & 1 \\
\hline DIST & Distance between the home and the nearest watercourse $(\mathrm{km})$ & 0.445 & 0.567 & 0.004 & 5.466 \\
\hline WRIS & Rising water in the case of a flood & 0.11 & 0.31 & 0 & 1 \\
\hline APAR & Apartment house & 0.108 & 0.31 & 0 & 1 \\
\hline RISK & $\begin{array}{l}\text { Agrees with the statement: "The fluvial flood risk is high in the } \\
\text { area where I live." }\end{array}$ & 0.41 & 0.492 & 0 & 1 \\
\hline PROP & Considers owning properties in danger of flooding & 0.53 & 0.499 & 0 & 1 \\
\hline DAMA & Has experienced damage or harm because of fluvial floods & 0.274 & 0.446 & 0 & 1 \\
\hline IMPL & Has implemented flood mitigation measures & 0.089 & 0.285 & 0 & 1 \\
\hline WTP & Willing to pay for new private protection measures & 0.081 & 0.273 & 0 & 1 \\
\hline INSU & Is aware of having home insurance with fluvial flood coverage & 0.105 & 0.307 & 0 & 1 \\
\hline CONS & Willing to consider purchasing insurance with flood coverage & 0.181 & 0.385 & 0 & 1 \\
\hline ATTI & $\begin{array}{l}\text { Agrees with the statement: "Households can influence the } \\
\text { damage caused by fluvial floods." }\end{array}$ & 0.217 & 0.413 & 0 & 1 \\
\hline INFO & Obtained new information from the questionnaire & 0.307 & 0.461 & 0 & 1 \\
\hline TRUS & Trusts in the ability of the authorities to plan mitigation measures & 0.468 & 0.499 & 0 & 1 \\
\hline
\end{tabular}

Table 1. Summary of the statistics for the variables used to model the willingness to apply private mitigation measures and to purchase flood insurance.

\subsection{Factors influencing willingness to implement mitigation measures}

Logistic regression analysis was carried out to investigate which attributes influenced the probability of respondents implementing private mitigation measures on their property. The coefficients of eight variables were statistically significant at the $0.5 \%$ level and of the expected sign.

The variables age and distance (AGE, DIST) had a statistically significant negative impact on the willingness to apply private mitigation measures. The distance from the household to the river causing the flood risk had an effect on the willingness to apply mitigation measures. The further the river was from the respondent's home, the lower was the household's willingness to apply mitigation measures. Furthermore, younger respondents were more likely to apply measures than older respondents.

A higher willingness was most strongly associated with earlier experience of flood damage (DAMA) and having a property at risk $(P R O P)$ : if the respondent had experienced flood damage during the previous ten years or felt that his or her property was in danger because of flooding, the probability of considering new mitigation measures (or having already implemented these measures) increased.

In addition, the willingness to consider mitigation measures increased with a positive attitude towards or belief in the household's ability to influence the damage caused by floods (ATTI) and on receiving new information on floods and flood protection measures from the survey $(I N F O)$. Finally, a higher willingness to implement private protection measures was associated with having or considering the purchase of flood insurance (INSU and CONS).

Several factors had no statistically significant influence on the willingness to apply mitigation measures. These included the variables ENTR, WRIS, $A P A R, R I S K$ and TRUS, indicating that being a farmer or a forest entrepreneur, living in an apartment house, agreeing with the statement: "The fluvial flood risk is high in the area where I live" and trust in flood risk authorities were not factors influencing the preparedness to implement private mitigation measures. In addition, the computational variable WRIS, indicating whether the water level would rise to the respondent's property in case of a fluvial flood, was not associated with a higher willingness to implement measures.

Table 2 presents the estimation results. The pseudo $\mathrm{R}^{2}$ is 0.34 , which indicates a good fit for this type of model. The model can be written as:

\footnotetext{
logit ("mitigation measures") $=-1.389-$

$0.025^{*} A G E+1.377^{*} P R O P+1.575^{*} D A M A+$ $0.735 * A T T I+0.593 * I N F O-0.599 * D I S T+$ $0.595 * I N S U+0.696 *$ CONS
} 


\begin{tabular}{|c|c|c|c|}
\hline Variable & B (S.E.) & Sig. & $\operatorname{Exp}(B)$ \\
\hline Constant & $-1.389(0.605)$ & 0.022 & 0.249 \\
\hline AGE & $-0.025(0.006)$ & $0.000 * * *$ & 0.976 \\
\hline FEMA & $0.242(0.175)$ & 0.168 & 1.274 \\
\hline ENTR & $0.047(0.209)$ & 0.821 & 1.049 \\
\hline DIST & $-0.599(0.16)$ & $0.000 * * *$ & 0.549 \\
\hline WRIS & $-0.049(0.229)$ & 0.83 & 0.952 \\
\hline APAR & $0.165(0.317)$ & 0.603 & 1.179 \\
\hline PROP & $1.377(0.216)$ & $0.000 * * *$ & 3.964 \\
\hline DAMA & $1.575(0.186)$ & $0.000 * * *$ & 4.831 \\
\hline INSU & $0.595(0.19)$ & 0.012* & 1.814 \\
\hline CONS & $0.696(0.19)$ & $0.000 * * *$ & 2.007 \\
\hline RISK & $0.172(0.18)$ & 0.338 & 1.188 \\
\hline ATTI & $0.735(0.183)$ & $0.000 * * *$ & 2.086 \\
\hline INFO & $0.593(0.175)$ & $0.001 * *$ & 1.81 \\
\hline TRUS & $-0.12(0.172)$ & 0.484 & 0.887 \\
\hline \multicolumn{2}{|c|}{ Correct predictions } & \multicolumn{2}{|l|}{$87.0 \%$} \\
\hline \multicolumn{2}{|c|}{ Cox \& Snell $\mathrm{R}^{2}$} & \multicolumn{2}{|l|}{0.193} \\
\hline \multicolumn{2}{|c|}{ Nagelkerke $\mathrm{R}^{2}$} & \multicolumn{2}{|l|}{0.338} \\
\hline \multicolumn{2}{|c|}{-2 Log likelihood } & \multicolumn{2}{|l|}{995.115} \\
\hline \multicolumn{2}{|c|}{ Chi-square (df) } & \multicolumn{2}{|c|}{$179.18(14), p=0.000$} \\
\hline \multicolumn{2}{|l|}{$\mathrm{N}$} & \multicolumn{2}{|l|}{1,586} \\
\hline
\end{tabular}

Table 2. Results of a binary logistic regression model in which the dependent variable was either the household's willingness to consider applying new mitigation measures or having already implemented mitigation measures.

Level of significance: $* * * p<0.001, * * p<0.01, * p<0.05$

\subsection{Factors influencing the willingness to purchase flood insurance}

Next, the influence of socio-economic and attitude variables on the probability of respondents being willing to purchase a flood insurance was analyzed with a binary logistic regression model. The coefficients of six variables were statistically significant at the $0.5 \%$ level and of the expected sign.

The negative coefficients of the variables age $(A G E)$ and apartment house $(A P A R)$ indicated that younger respondents and those who did not live in an apartment house were more likely to purchase flood insurance.

The positive coefficients of the variables entrepreneur $(E N T R)$, property in a fluvial flood risk area $(P R O P)$, having implemented private protection measures (IMPL), and willingness to pay for new mitigation measures in the future $(W T P)$ indicated that respondents who were farmers or forest entrepreneurs, who considered their property/assets to be at risk of flooding, and who had already implemented private protection measures on their property and/or stated willingness to pay for future private mitigation measures were more likely to belong to the group of flood insurance purchasers.
In addition, the results indicated that receiving new information about floods (and flood risk management) from the survey questionnaire (INFO) increased the probability of the respondent belonging to the purchasers' group, i.e. these respondents were more likely to be interested in flood insurance.

Interestingly, several factors were not associated with willingness to purchase flood insurance. These included the respondent's gender (FEMA), distance between the home and the nearest water body $(D I S T)$, whether the water level could theoretically rise to the level of the respondent's property in case of a fluvial flood (WRIS), former experience of damage caused by fluvial floods (DAMA), the respondent's trust in the authorities to plan flood protection measures (TRUS), or the attitude that households can influence the damage caused by fluvial floods (ATTI).

Table 3 presents the estimation results. The pseudo $\mathrm{R}^{2}$ is 0.15 , which indicates a satisfactory fit for this type of model. The model can be written as:

logit ("flood insurance") $=0.577-0.014 * A G E+$ $0.336^{*} E N T R E-0.988^{*} A P A R+0.607 * P R O P+$ $0.599 * I M P L+1.244 * W T P$

\begin{tabular}{lccc}
\hline Variable & B (S.E.) & Sig. & $\operatorname{Exp}(\mathrm{B})$ \\
\hline Constant & $0.577(0.429)$ & 0.178 & 1.78 \\
AGE & $-0.014(0.004)$ & $\mathbf{0 . 0 0 1} * *$ & 0.986 \\
FEMA & $-0.012(0.118)$ & 0.917 & 0.988 \\
ENTR & $0.336(0.159)$ & $\mathbf{0 . 0 3 5} *$ & 1.399 \\
DIST & $0.003(0.118)$ & 0.981 & 1.003 \\
WRIS & $-0.165(0.193)$ & 0.392 & 0.848 \\
APAR & $-0.988(0.191)$ & $\mathbf{0 . 0 0 0} * * *$ & 0.372 \\
PROP & $0.607(0.118)$ & $\mathbf{0 . 0 0 0} * * *$ & 1.835 \\
DAMA & $0.177(0.154)$ & 0.252 & 1.193 \\
IMPL & $0.599(0.268)$ & $\mathbf{0 . 0 2 6} *$ & 1.82 \\
WTP & $1.254(0.283)$ & $\mathbf{0 . 0 0 0} * * *$ & 3.506 \\
RISK & $0.164(0.125)$ & 0.191 & 1.178 \\
ATTI & $0.199(0.136)$ & 0.144 & 1.22 \\
INFO & $0.217(0.125)$ & 0.083 & 1.242 \\
TRUS & $-0.001(0.114)$ & 0.995 & 0.999 \\
\hline
\end{tabular}

Correct predictions

$64.1 \%$

Cox \& Snell $\mathrm{R}^{2}$

0.111

Nagelkerke $\mathrm{R}^{2}$

0.15

-2 Log likelihood

1886.261

Chi-square (df)

179.18 (14), $\mathrm{p}=0.000$

$\mathrm{N}$

1,519

Table 3. Results of a binary logistic regression model in which the dependent variable is the willingness of respondents living in a significant flood risk area to purchase or to consider purchasing flood insurance.

Level of significance: ${ }^{* * *} \mathrm{p}<0.001,{ }^{* *} \mathrm{p}<0.01,{ }^{*} \mathrm{p}<0.05$ 


\section{Discussion}

This study was the first to investigate the attitudes of Finnish homeowners towards and willingness to apply mitigation measures and/or purchase flood insurance and to more closely assess the factors influencing these intentions. The modeling of both of these with logistic regression models and the fact that the study data were derived from the same questionnaires differentiates our study from most others.

In earlier studies, only a few socioeconomic and geographical factors have consistently been related to flood mitigation behavior [1]. Our results demonstrated that younger respondents were more willing to implement private mitigation measures and purchase flood insurance than older respondents. The gender of the respondents had no influence on either of the intentions to reduce the damage from or risk of flooding. This contradicts the study of Botzen et al. [3], who found women to be less willing to pay for flood insurance than men. In many previous studies, the distance to a river or water body has appeared to have little effect on actual mitigation behavior [1, 4]. However, in our study, this factor did have an influence on the willingness of respondents to apply private mitigation measures on their property, but not on the purchasing of flood insurance.

Thieken et al. [9] observed that those who had flood insurance had also taken more action during a flood. Similarly, according to Oulahen [6], undertaking mitigation measures had a significant positive association with the WTP for flood insurance. Atreya et al. [10] obtained somewhat similar results in their Georgian study. Our results are in accordance with these findings. Implementing private measures and purchasing flood insurance can be seen as complementary actions, since those respondents who were most willing to implement mitigation measures were also willing to consider purchasing flood insurance, and vice versa. In other words and as our logit models clearly show, among some other variables (e.g. having property in a fluvial flood risk area), willingness to pay for mitigation measures explains willingness to purchase flood insurance, and vice versa.

We also included a variable, WRIS, describing whether the real estate of the respondents was at risk of flooding according to GIS analysis. Perhaps surprisingly, this factor was not significant for either mitigation measures or the WTP for insurance. There could be many reasons for this. For instance, people might only consider the distance to the river as a risk factor, although the difference in altitude between their real estate and the river might be quite small. Therefore, it would be interesting to conduct an otherwise similar study, but accompanied by a flood map for each real estate with the probabilities of different water level rises and examine whether the variable WRIS would then be a significant factor.

The majority of the literature reviewed by Bubeck et al. [1] suggested a positive relationship between fear or worry about flooding and the adoption of flood mitigation measures. However, in our study, this attribute (RISK) had no influence on either insurance or mitigation measures.

According to Bubeck et al. [1], experience of flooding (i.e. the severity of the experienced negative consequences) was an explanatory variable for mitigation behavior in almost all their reviewed studies. Botzen et al. [11] demonstrated that experience of flooding is positively related to the demand for flood insurance, i.e. it is an important factor influencing private mitigation behavior. Both papers came to the conclusion that a positive relationship exists between emotional items such as fear or worry about flooding and the adoption of flood mitigation measures. However Oulahen [6] found that there was no significant association between the WTP for flood insurance and previous experience of a flood in a Canadian study.

Our results are partly in accordance with the study of Oulahen, as we also found no significant association between the WTP for flood insurance and previous experience of flooding. However, residents with previous flood experiences were more likely to have carried out private mitigation measures or be willing to do so than residents without these types of experiences.

Knowledge has not always been a very useful predictor of flood mitigation behavior [1]. Zalewskiewicz et al. [5] found no significant differences in terms of knowledge about floods between respondents who bought flood insurance and those who did not. In our study, if respondents felt that they had learned something new from the questionnaire, they were also more likely to invest in private flood protection measures, but this did not affect their interest in purchasing insurance. This was also true if they felt that their household was able to influence the damage caused by fluvial floods. If the respondents felt that they had property at risk, they were likely to take both precautions, i.e. flood protection measures and insurance.

Interestingly, living in a detached house instead of an apartment house was only a significant determinant for taking out or already having insurance, and not for protection measures. Trust in the ability of the authorities to plan flood mitigation methods was not a significant determinant for either implementing private flood protection measures or purchasing flood insurance.

\section{Conclusions}

Although Finnish floods might appear minor compared to flood damage elsewhere, e.g. in Central Europe, they are the most serious natural hazards in Finland. During a typical flood year, compensation paid by the government to private citizens has totaled almost one million euros. The compensation mechanism has now changed, but experiences of insurance-based compensation are still rare. We were interested in exploring how Finnish people have prepared for floods, whether it is through private mitigation measures or taking out insurance coverage in case of flooding, and what factors influenced their decisions.

First of all, we found that people who had carried out flood mitigation measures or planned to do so were 
also more likely to have insurance policies with flood coverage, and vice versa. That is to say, these measures were complementary to each other, not exclusive.

There were also more variables explaining willingness to pay for property-specific flood mitigation measures than there were variables explaining the interest in flood insurance. For example, belief in the household's capability to influence flood damage and receiving new flood-related information were significant in explaining the willingness to implement flood mitigation measures, but not to purchase flood insurance. In any case, this appears to be an incentive to inform residents living in flood-prone areas about how to protect their property against floods. The same notion has also been presented in other studies $[1,2]$. However, landowners were more interested in insurance.

Furthermore, younger people were more interested in both mitigation measures and flood insurance policies. This can be seen as a promising sign and should be taken into account when planning information campaigns. Many respondents also wished for more information on how to protect their property, i.e. concrete measures and advice. Trust in the ability of the authorities to plan flood mitigation measures was not a significant factor influencing the willingness to either implement mitigation measures or purchase insurance.

However, as mentioned earlier, the average damage caused by floods in Finland is not particularly significant on a global scale. This is probably why there are currently no specific flood insurance policies, but water damage caused by flooding is included in most home insurances. However, if more severe flood incidents occur in the future, this might change the situation and create a new line of business for Finnish insurers.

Oulahen [6] reported increasing media coverage in Canada concerning the frustration among home owners on learning that their insurance policy does not cover damage caused by flooding. It remains to be seen whether something like this will also happen in Finland after the first major flooding and when people realize that the compensation practices have at least in some parts been tightened. This might more probably be the scenario if real estates suffering from the floods are uninsured and if building permission has been granted for areas that are too low-lying. In such a case, is the responsible party the owner or the administrator of the building permissions?

\section{Acknowledgements}

The authors would like to thank water and flood risk management experts from the regional Centres for Economic Development, Transport and the Environment of North Ostrobothnia, South Ostrobothnia, and Southwest Finland, and also Pekka Kinnunen, Mikko Sane, and Mikko Huokuna from the Finnish Environment Institute, for their assistance with this article in its different stages. This research was enabled by the BASE (Bottom-Up Climate Adaptation Strategies for a Sustainable Europe) project, funded by the EU 7th
Framework Programme for Research, Technological Development and Demonstration. This work has also been funded by the Ministry Agriculture and Forestry and the Finnish Environment Institute.

\section{References}

1. Bubeck P., Botzen W.J.W. and Aerts J.C.J.H. (2012). A review of risk perceptions and other factors that influence flood mitigation behavior. Risk Analysis, Vol 32(9), pp. 1481-1495.

2. Bradford R. A., O'Sullivan J. J., van der Craats I. M., Krywkow J., Rotko P., Aaltonen J., Bonaiuto M., De Dominicis S., Waylen K. and Schelfaut K. (2012). Risk perception-issues for flood management in Europe. Natural Hazards and Earth System Science, Vol 12(7), pp. 2299-2309.

3. Botzen W.J.W., Aerts J.C.J.H. and van den Bergh J.C.J.M. (2009). Willingness of homeowners to mitigate climate risk through insurance, Ecological Economics, Vol 68(6-8), pp. 2265-2277.

4. Wachinger G., Renn O., Begg C. and Kuhlicke C. (2013) The Risk Perception Paradox-Implications for Governance and Communication of Natural Hazards, Risk Analysis, Vol 33, pp. 1049-1065.

5. Oulahen G. (2015) Flood Insurance in Canada: Implications for Flood Management and Residential Vulnerability to Flood Hazards, Environmental Management, Vol 55 (2015), pp. 603-615.

6. Dillman D. A. (1978). Mail and Telephone Surveys: The Total Design Method, New York: Wiley.

7. Bateman I., Carson J. R., Day T. B., Hanemann M., Hanley N., Hett T., Jones Lee M., Loomes G., Mourato S., Özdemiroglu E., Pearce D., Sudgen W. R. and Swanson J. (2002) Economic Valuation with Stated Preference Techniques: A Manual, Edward Elgar, Cheltenham, UK.

8. Thieken A.H., Petrow T., Kreibich H. and Merz B. (2006). Insurability and mitigation of flood losses in private households in Germany, Risk Analysis, Vol 26, pp. 383-395.

9. Botzen W.J.W. and van den Bergh J.C.J.M.. (2012) Risk attitudes to low-probability climate change risks: WTP for flood insurance, Journal of Economic Behavior \& OrganiZation, Vol 82 (1), pp. 151-166.

10. Zaleskiewicz T., Piskorz Z. and Borkowska A. (2002). Fear or money? Decisions on insuring oneself against flood. Risk, Decision and Policy, Vol 7, pp. 221-233. doi:10.1017/S1357530902000662.

11. Atreya A., Ferreira S. and Michel-Kerjan E. (2015). What drives households to buy flood insurance? New evidence from Georgia. Ecological Economics, Vol 117, pp. 153-161. 